\title{
Forehead Donor Site Full-Thickness Skin Graft
}

\author{
Vassilios Dimitropoulos, MD, ${ }^{*}$ Christopher K. Bichakjian, MD, \\ And Timothy M. JOHnson, MD*t+ \\ Departments of ${ }^{*}$ Dermatology, ${ }^{\dagger}$ Otolaryngology, and ${ }^{\star}$ Surgery, University of Michigan Medical School, Ann Arbor, Michigan
}

BACKGROUND. Full-thickness skin grafts (FTSGs) are useful for reconstructing nasal defects. Traditional reported donor sites include the preauricular, postauricular, supraclavicular, clavicular, conchal bowl, melolabial fold, and upper eyelid skin. Selection of the "best" donor site is based on the "best" tissue match and ability to camouflage the donor scar.

OBJECTIVE. The purpose was to report our experience with FTSGs harvested from the forehead for reconstruction of nasal defects following Mohs' surgery.

METHODS. A retrospective query of the Mohs' surgery database was performed to identify nasal defects repaired with a FTSG harvested from the forehead skin. The research record contained the patient age and gender, defect size, and cosmetic and functional outcomes interpreted by the patient and surgeon. RESULTS. FTSGs from forehead skin were used to repair the nasal defects in three patients. The functional and cosmetic outcome of all three cases was deemed excellent by the patient and surgeon. Donor site scars were well concealed within preexisting rhytids.

CONCLUSION. FTSGs harvested from the forehead, although limited in practical utility, may offer an optimal FTSG match for limited select defects while also providing an easily camouflaged donor site scar within a forehead rhytid.

VASSILIOS DIMITROPOULOS, MD, CHRISTOPHER K. BICHAKJIAN, MD, AND TIMOTHY M. JOHNSON, MD, HAVE INDICATED NO SIGNIFICANT INTEREST WITH COMMERCIAL SUPPORTERS.

THE INCIDENCE of skin cancer continues to rise in the United States, with nonmelanoma skin cancer occurring at a rate of over a million new cases annually. Many of these skin cancers occur on the nose and require excision and reconstruction for definitive therapy. Dermatologists have led the way in advancing the field of dermatologic surgery. A mental assessment of all available reconstructive options of defects following skin cancer excision is of the utmost importance in achieving optimal functional and cosmetic results. The nose often presents several challenges, which include patient, defect, structural, and free margin considerations. A myriad of reconstruction options are often available. Both immediate and delayed full-thickness skin grafts (FTSGs) often represent a viable option for nasal reconstruction. ${ }^{1,2} \mathrm{~A}$ search for the "best" graft donor site usually pertains to the most appropriate match with respect to tissue thickness, photo damage, color, adnexal quality, and texture. The objective herein is to report our experience using a FTSG harvested from forehead skin for the repair of nasal defects following Mohs' surgery. Although practical utility is seemingly limited, the forehead donor site may offer an optimal FTSG match for limited select defects while also providing an easily camouflaged donor site scar within a forehead rhytid.

Address correspondence and reprint requests to: Timothy M. Johnson, MD, University of Michigan Health System, 1910 Taubman Center, 1500 E. Medical Center Drive, Ann Arbor, MI 48109-0314, or e-mail: timjohn@med.umich.edu.

\section{Methods}

Study approval was granted by the University of Michigan Institutional Review Board for Human Research Subjects. A retrospective query of the University of Michigan Mohs' surgery database from July 2002 to January 2004 revealed three patients with nasal defects reconstructed with a FTSG harvested from forehead skin following Mohs' excision of skin cancer. Selection of the "best" donor site in these three patients was based on the "best" tissue match and ability to camouflage the donor scar. The research record for these patients contained the patient age and gender, defect size, and cosmetic and functional outcomes interpreted by the patient and surgeon.

Selection of the donor site was made in terms of tissue quality, color, texture, thickness, and size. Forehead skin occurring in a rhytid offered an excellent "best" match in three patients. These three lacked sufficiently loose adjacent tissue for local flap reconstruction, and the defects were deeper than the thickness of a FTSG harvested from a traditional donor site and/or required immediate reconstruction. A template of the defect was placed over the forehead donor site within a rhytid. The donor site was marked prior to infiltration with anesthetic to prevent transient distention of the donor tissue. The donor graft was excised to the level of adipose tissue and placed in a sterile saline. The donor site was closed primarily within an existing facial rhytid for optimal cosmesis. The graft was defatted using sharp scissors to the level of the dermis. The graft was placed in the recipient 
site, trimmed for a perfect fit, and secured using perimeter sutures and a pyramid tie-over bolster. The dressing was removed at 1 week. Following suture removal, instructions were given to gently cleanse the graft with hydrogen peroxide on a cotton tip to remove crusts. Patients were counseled regarding graft fragility and avoidance of rigorous activities or direct trauma to ensure the best possible outcome.
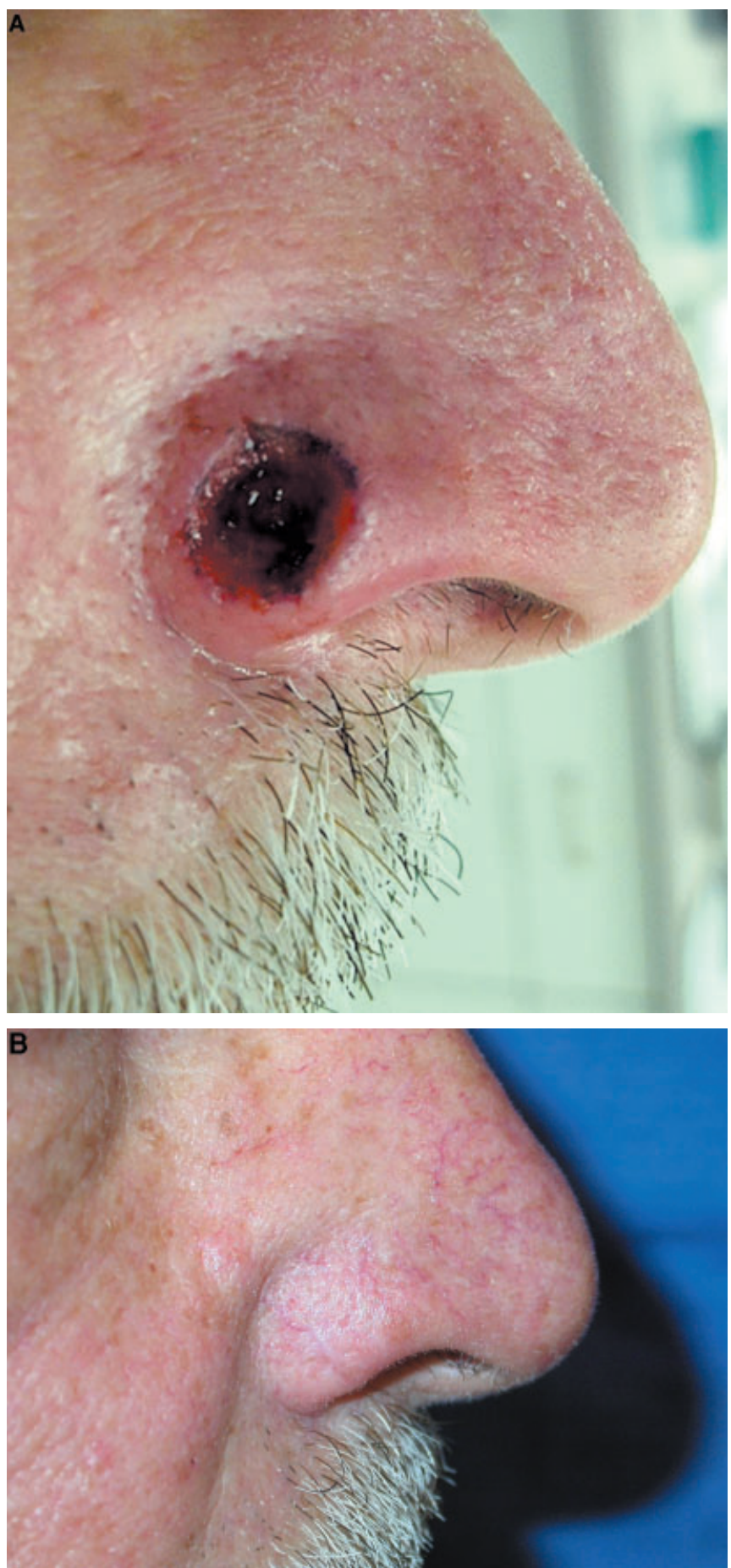

\section{Results}

The three nasal defects closed with a FTSG harvested from forehead skin were $0.8 \times 0.9 \mathrm{~cm}, 0.8 \times 0.9 \mathrm{~cm}$, and $1.0 \times 1.0 \mathrm{~cm}$ and approximately $3 \mathrm{~mm}$ deep. Two
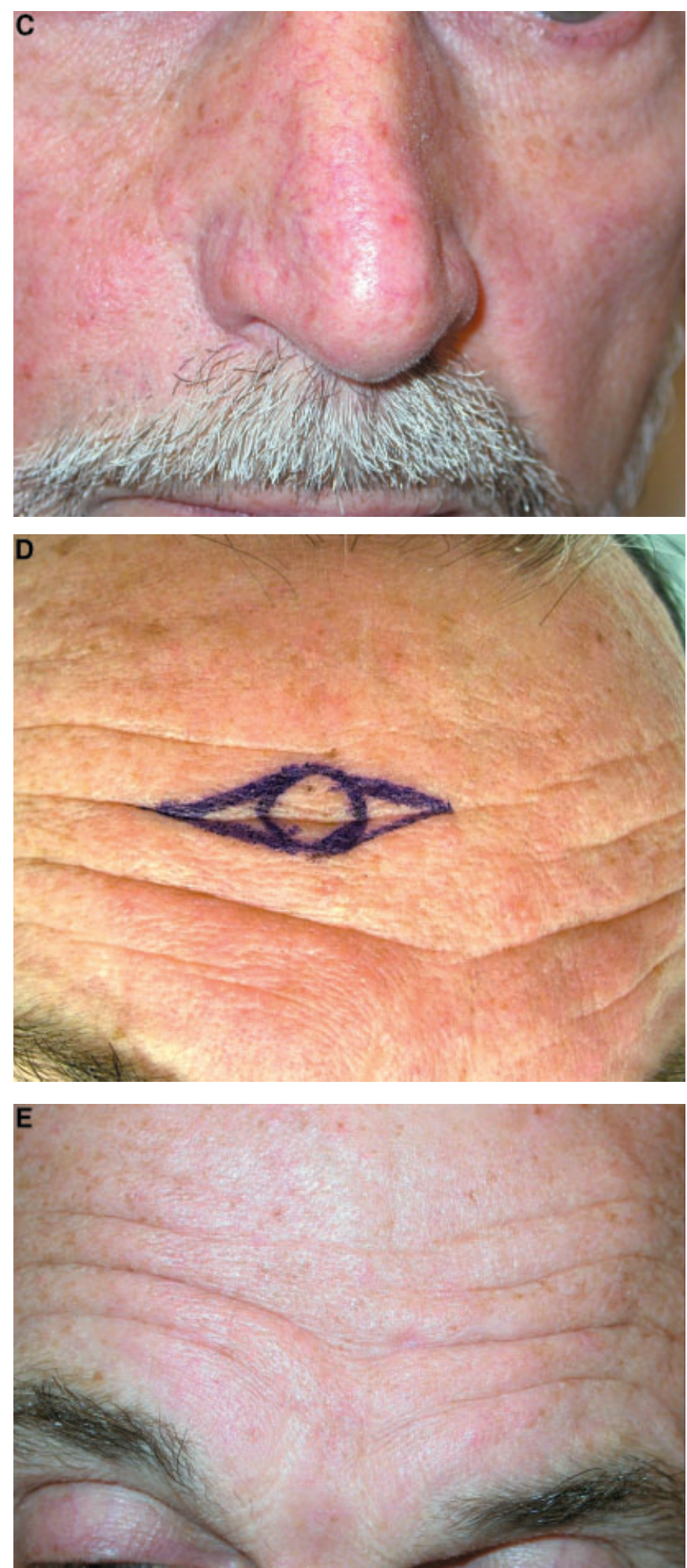

Figure 1. (A) Mohs' defect; (B) 11 months postoperatively; (C) 11 months postoperatively; (D) donor site; (E) donor site, 11 months postoperatively. 
were men aged 64 and 59 years, and one was a woman of 86 years. All three had traditional donor sites that were significantly thinner than the primary defect and with a poor tissue match. All three had prominent forehead rhytids and excellent forehead skin tissue quality and thickness match. The defects were located on the nasal ala in two patients and the nasal dorsum bridge in one patient. The functional and cosmetic outcome for all three patients was deemed excellent by the patient and physician with follow-up $>6$ months. All three patients healed with a minimal scar, with excellent contour, color, and texture tissue match (Figure 1). Secondary revision dermabrasion was not required for any of the patients.

\section{Discussion}

Full-thickness defects of the nose most commonly result following skin cancer excision in dermatologic surgery. After removal of these skin cancers, the dermatologic surgeon often confronts a reconstructive challenge. A number of reconstructive options usually exist for any given nasal defect, most commonly including granulation, layered closure, local or staged flaps, and FTSGs. Approaching the defect and patient in an individualized fashion, using a mental exercise to assess the advantages and disadvantages of each closure option, provides the best chance of an optimal functional and cosmetic end result. Knowledge of the indications, techniques, patient and defect considerations, and complications of all types of reconstructive options is necessary to provide optimal reconstruction. ${ }^{3,4}$

FTSGs are useful for reconstructing small and large nasal defects. They are most useful when recruitment of adjacent local tissue is suboptimal owing to a lack of an adequate tissue reservoir or when a local flap will result in distortion of surrounding structures or free margins. The most commonly reported donor sites used in dermatologic surgery for FTSGs are preauricular, postauricular, supraclavicular, clavicular, conchal bowl, upper eyelid, and melolabial fold skin. ${ }^{1,2,5-7}$ Selection of the "best" donor site is based on the "best" tissue match and the ability to camouflage the donor scar.

We have learned that the forehead flap often offers an ideal reconstructive result owing to excellent tissue match. ${ }^{8}$ However, the associated morbidity and multiple stages represent a significant disadvantage. Use of forehead skin as a FTSG may provide a similar excellent tissue match in limited selected cases. The forehead graft may also be thicker in some patients compared with other donor sites, making this donor area better for defects deeper than conventional FTSG donor sites. Depending on the anatomic site, both overall skin thinning and thickening occur with increased age. Typically, chronologic aging is characterized by pro- gressive skin thinning, whereas photoaging is associated with overall skin atrophy, preceded by a transient hypertrophic stage (biphasic). In some elderly patients, traditional donor sites are $\leq 1 \mathrm{~mm}$ thick and result in permanent contour defects if used for defects approaching $3 \mathrm{~mm}$ thick. The overall thickness of forehead, ear, and nose skin increases with increasing age. ${ }^{9}$ Forehead skin thickness is variable, typically ranging from 1.5 to $4.0 \mathrm{~mm} .{ }^{10-12}$ The disadvantage of a thicker graft, of course, is a requirement for a well-vascularized recipient bed without associated factors, such as smoking for graft survival. The thicker the graft, the greater the need for a supportive recipient bed and the greater the chance of graft failure. For larger defects, repairing a forehead donor site would be a formidable challenge and would likely result in a large, unsightly scar that would be incompletely hidden in existing rhytids in a patient without prominent rhytids. For patients with prominent rhytids, however, the donor site is easily camouflaged. The donor site was easily hidden in a horizontal forehead rhytid in two of our patients and a glabellar crease in one patient. It should be emphasized that the forehead graft is not usually our first choice to reconstruct nasal defects. However, it provides another useful option to add to our armamentarium and has yielded superior results in selected cases.

\section{References}

1. Johnson TM, Ratner D, Nelson BR. Soft tissue reconstruction with skin grafting. J Am Acad Dermatol 1992;27:151-65.

2. Robinson JK, Dillig G. The advantages of delayed nasal full-thickness skin grafting after Mohs micrographic surgery. Dermatol Surg 2002; 28:845-51.

3. Robinson JK. Segmental reconstruction of the face. Dermatol Surg 2004;30:67-74.

4. Johnson TM, Swanson N, Baker SR. Concepts of sliding and lifting tissue movement in flap reconstruction. Dermatol Surg 2000;26:274-8.

5. Love CW, Collison DW, Carithers JS, Ceilley RI. Perichondrial cutaneous grafts for reconstruction of skin cancer excision defects. Dermatol Surg 1995;21:219-22.

6. Rohrer TE, Dzubow LM. Conchal bowl skin grafting in nasal tip reconstruction: clinical and histologic evaluation. J Am Acad Dermatol 1995;33:476-81.

7. Matheson BK, Mellette JR Jr. Surgical pearl: clavicular grafts are "superior" to supraclavicular grafts. J Am Acad Dermatol 1997;37: 991-3.

8. Boyd CM, Baker SR, Fader DJ, et al. The forehead flap for nasal reconstruction. Arch Dermatol 2000;136:1365-70.

9. Gniadecka M, Jemec GB. Quantitative evaluation of chronological ageing and photoageing in vivo: studies on skin echogenicity and thickness. Br J Dermatol 1998;139:815-21.

10. Seidenari S, Giusti G, Bertoni L, et al. Thickness and echogenicity of the skin in children as assessed by $20-\mathrm{MHz}$ ultrasound. Dermatology 2000;201:218-22.

11. Dahan S, Lagarde JM, Turlier V, et al. Treatment of neck lines and forehead rhytids with a nonablative 1540-nm Er:glass laser: a controlled clinical study combined with the measurement of the thickness and the mechanical properties of the skin. Dermatol Surg 2004;30:872-9.

12. Gunga HC, Kirsch K, Baartz F, et al. Fluid distribution and tissue thickness changes in 29 men during 1 week at moderate altitude (2,315 m). Eur J Appl Physiol Occup Physiol 1995;70:1-5. 